\title{
Educar para a Economia de Francisco: possíveis contribuições do Setor de Cultura Religiosa da PUC-Rio
}

\section{Abimar Oliveira de Moraes $^{1}$}

Ao convocar os jovens para o evento a "Economia de Francisco", o Papa Francisco recordava que as universidades precisam ser "canteiros de esperança para construir outras modalidades de entender a economia e o progresso, para combater a cultura do descarte, para dar voz a quantos não a têm, para propor novos estilos de vida".

Por esta razão, no ano de 2020, celebrando os 80 anos da PUC-Rio, mas, também, de sua missão universitária, a Cultura Religiosa se propôs a discutir, juntamente com seus discentes e especialistas, os caminhos de reverência, cuidado, fraternidade e diálogo com o planeta Terra a partir da vivência que Francisco e Clara tiveram do Evangelho.

Ao definir a universidade como "canteiro da esperança", o Papa Francisco convida a assumir a alegre tarefa de educar para o futuro. A Cultura Religiosa encontra-se no elenco das formas de educação abertas ao futuro. Encontra-se, portanto, constitutivamente no campo da aspiração de fazer com que os discentes com quem dialoga avancem nos processos de humanização, tornando-se, sempre mais, cidadãos do futuro histórico, enquanto mediação necessária do futuro que o fenômeno religioso e, dentro dele, a fé cristã definirão como futuro último.

O futuro histórico deve assumir uma valência projetual e operativa, pois o futuro último, não virá sem a colaboração humana, sem empenho, sem militância. Por isso, o futuro histórico traz consigo uma precisa dimensão ética. O futuro histórico representa uma dimensão essencial do empenho ético cristão e, portanto, um desafio e um problema para todo tipo de educação cultural que se inspira na experiência religiosa.

Durante muito tempo a educação ética não teve que enfrentar o problema do futuro como problema ético. Um futuro era uma espécie de entidade cronológica, uma repetição do passado, um horizonte imóvel e insignificante para ação humana no presente. O único futuro diverso conhecido era o futuro último, mas concebido de forma tão separada do tempo histórico que se tornou não influente do ponto de vista ético.

De algumas décadas para cá, temos sido convidados e convidadas a entender que o futuro intra-histórico deve ser plasmado pelas mãos humanas de modo consciente e responsável. O futuro não é uma repetição do passado, mas sim, uma tarefa ética. Assim, a educação cultural religiosa começou a colocar-se, de maneira consciente, o problema do futuro como algo sobre a qual essa deve influir, seja participando do processo que plasma o futuro,

\footnotetext{
${ }^{1}$ Doutor em Teologia pela Pontificia Università Salesiana (Roma), professor do Departamento de Teologia da PUCRio e Coordenador do Setor de Cultura Religiosa da PUC-Rio.
} 
mas, sobretudo, ajudando os construtores e construtoras deste futuro, isto é, os verdadeiros protagonistas do futuro: as novas gerações que o formarão e nele viverão.

A aceleração crescente das transformações sociais e econômicas, dos ritmos da história, a rapidez de nossos dias que torna o futuro sempre mais imprevisível, tornam, sempre mais, importante as responsabilidades que a educação cultural religiosa tem em relação ao futuro.

Dentre os diversos aspectos que se encontram, na sociedade, em rápida transformação, a realidade econômica está certamente entre as que mais chamam a atenção e despertam preocupação em nossos tempos. A partir da revolução industrial, a realidade econômica conheceu um crescimento cumulativo tão intenso e acelerado que o próprio termo desenvolvimento passou a servir para designar habitualmente sobretudo o desenvolvimento econômico, considerado como princípio dinâmico e motor de todas as outras formas de desenvolvimento.

Dentro desse contexto surge uma série de interrogativos. Educar para qual sociedade? Educar para qual futuro? Educar para qual tipo de desenvolvimento? Já há muito tempo em que a riqueza econômica vem sendo considerada um prêmio que está vinculado a certas virtudes que precisamos desenvolver: diligência no trabalho; parcimônia; previdência; poupança. Com a consolidação do Capitalismo se adicionaram a esse elenco tradicional as virtudes do empreendedorismo, do investimento de risco, da inventividade e, até mesmo, da agressividade. Especialmente, essa última gerou certa insensibilidade em relação aos outros e outras.

Contudo, vamos dando conta que o desenvolvimento se tornou um problema de dimensão mundial ligado à crescente desigualdade econômica planetária. Nesse contexto, a relação entre educação, futuro do mundo e desenvolvimento sustentável se torna de crucial importância.

Assim, o tipo de desenvolvimento até agora pensado, programado e realizado não pode continuar em virtude da finitude insuperável dos recursos não renováveis do planeta, do acúmulo progressivo de poluição produzido pela atividade industrial que degrada de modo irreversível os delicados ecossistemas existentes no mundo e do conjunto de fenômenos de degradação e desordem social que se apresentam como subproduto do desenvolvimento e da urbanização selvagem.

A consciência aguda da urgência desses problemas, sobretudo, os ligados à limitação dos recursos naturais não renováveis e aos perigos da destruição dos ecossistemas naturais necessários para a vida de diversas espécies, inclusive a humana, vem gradualmente se difundindo. Assistimos, assim, o surgimento de diversos movimentos, informais e estruturados, de caráter cultural, social, político, voltados a formar a consciência acerca da exigência de intervenções radicais em vista da salvaguarda do ambiente natural, como condição de sobrevivência para a humanidade e como única via para a preservação ou a restauração da qualidade de vida. 
A ecologia vem tornando-se, assim, em níveis diversos, mas complementares, uma sensibilidade difusa, um programa de intervenções econômicas e políticas, uma verdadeira e específica disciplina científica, integrada plenamente no organismo das ciências humanas, sociais e da vida, mas, também, uma opção ética e um objetivo educativo de primária importância.

Nesse contexto, consequentemente, a educação religiosa é chamada a recuperar os valores positivos da consciência ecológica, principalmente no aspecto de empenho ético. A descoberta da vulnerabilidade do ambiente natural e a irreversibilidade de algumas situações provocadas pelos processos tecnológicos põem a consciência humana diante de um capítulo ético até então inexplorado, mas de suma e decisiva importância.

Diante dessa situação radicalmente nova, o gênero humano tem responsabilidades novas, uma vez que, no plano do conhecimento, é chamado a refletir sobre essas novas e imprevisíveis realidades que chamam em causa as suas responsabilidades com relação ao futuro e a sua consciência de que os riscos e as ameaças da tecnologia são mais decisivos que as suas promessas.

Numa situação em que não somente a qualidade do futuro, mas o próprio futuro está em risco, é preciso dar-se conta da importância da responsabilidade não recíproca com relação a pessoas que não tem nada a dar em troca, porque ainda não existentes.

Tal responsabilidade requer ações educativas que proponham uma nova concepção normativa da vida. Eis aqui, a moldura dentro da qual se apresenta a proposta "ecológica integral" que, desde o início do seu Pontificado, mas especificamente, em sua Encíclica Laudato Si', publicada em 2015, o Papa Francisco vem apresentando a todos os homens e mulheres de boavontade. Para o Papa Francisco, os problemas ecológicos estão em estreita conexão com os problemas econômicos e vice-versa.

A descoberta da vulnerabilidade do ambiente natural e de suas tantas situações de irreversibilidade ativadas pelos processos tecnológicos criticam a lógica do acúmulo de bens materiais e do descarte. A ética humana é posta diante de um capítulo de sua história, até agora, pouco explorado, mas de importância capital.

Diante desta situação radicalmente nova, a pessoa humana tem responsabilidades novas em relação à economia. Faz-se urgente a substituição de modelos éticos até aqui vigentes, por aquela que podemos considerar uma "ética do cuidado e da responsabilidade", pois a qualidade do futuro do mundo e da humanidade estão em jogo. Estamos diante de uma situaçãolimite que traz consigo a exigência da elaboração de "novas responsabilidades".

Para o Papa Francisco as "novas responsabilidades" do presente, em vista do futuro, podem encontrar uma analogia e uma confirmação num outro caso de responsabilidade e comportamento altruístico: a vivência que Francisco, Clara e demais companheiros tiveram do Evangelho. Reafirmamos: vivência do Evangelho. Ao insistirmos sobre o Evangelho, gostaria de nos transportar para a página do Evangelho de Mateus 20,1-16. 
Nela, Jesus é apresentado apelando para a vontade e o modo de agir de Deus, o futuro que Ele anuncia vem ao encontro do presente como evento que convida à fraternidade e à sororidade. Por isso, o relato bíblico apresenta-nos o comportamento de um dono de uma vinha, que dá a todos os trabalhadores um salário generoso (uma moeda de prata). Da primeira até a última hora em que saiu para convocar operários, sua atitude é constante e revela um modo de enxergar a todos e todas como iguais e, portanto, destinatários de sua abundância.

Assim, ao final da narrativa de Jesus, o dono da vinha dá aos trabalhadores da última hora o salário de um dia inteiro - nem mais nem menos - desmascarando a incapacidade dos trabalhadores da primeira hora de reconhecer que, aos olhos do dono da vinha, as divisões são desnecessárias.

A página do evangelho nos convida simplesmente a anular o privilégio de uns e superar a deficiência de outros. É a paridade que é afirmada. Uma paridade que tem como fundamento o reconhecimento de uma grande fraternidade/sororidade que nos convida a colocar de lado a posição de privilegiados, para assumirmos a condição de habitantes de uma mesma "casa comum".

Temos consciência de que esta não é uma tarefa fácil, por esta razão mesmo, a Cultura Religiosa da PUC-Rio é chamada a dar continuidade a algumas ações:

1) lluminar as raízes profundas, de natureza ética, de toda a problemática relativa ao desenvolvimento socioeconômico, aos limites deste desenvolvimento e à construção de uma ética do cuidado de si, dos outros humanos e do demais criados;

2) Conhecer e promover comportamentos pessoais e coletivos, já existentes, que nos permitam visualizar ações políticas e econômicas adequadas às responsabilidades objetivas para a construção de um novo futuro histórico que aqui, juntamente com o Papa Francisco, chamamos de "Economia de Francisco";

3) Subsidiar a elaboração de propostas concretas e promover opções e comportamentos de caráter profético que permitam a mobilização de energias éticas na construção de um novo;

4) Fornecer, à luz da sabedoria cristã, motivações e esperanças que sustentem as ações e as inevitáveis renúncias e sacrifícios que a seriedade e a dificuldade da situação atual nos impõem.

Mas a contribuição mais específica que, a partir da Cultura Religiosa, talvez possamos oferecer à solução dos problemas do desenvolvimento que se encontram no grupo dos problemas atuais mais graves da convivência humana, em nível mundial, consiste no anúncio de esperança e motivação de que é possível a construção de um novo, a partir de novas responsabilidades. É possível sonhar e, principalmente, consolidar a Economia de Francisco. 